\title{
First Korean case of a STAT1 gene mutation: chronic mucocutaneous candidiasis, hypothyroidism, chronic hepatitis and systemic lupus erythematosus
}

Kang-in Kim, Hanbyul Lee, So Yoon Jung, Dong Hwan Lee, and Jeongho Lee*

Department of Pediatrics, Soonchunhyang University Seoul Hospital, Seoul, Korea

Chronic mucocutaneous candidiasis (CMC) is characterized by increased susceptibility to chronic and recurrent infections of the skin, mucous membranes, and nails by Candida species. It is a primary immunodeficiency disorder that is difficult to diagnose because of its heterogeneous clinical manifestations and genetic background. A 20-month-old boy who did not grow in height for 3 months was diagnosed as having hypothyroidism and he had hepatitis which was found at 5 years old. He presented with persistent oral thrush and vesicles on the body, the cause of which could not be identified from laboratory findings. No microorganism was detected in the throat culture; however, the oral thrush persisted. Immunological tests showed that immunoglobulin (Ig) subclass $\lg G$ and cluster of differentiation (CD)3, CD4, and CD8 levels were within normal limits. We prescribed oral levothyroxine and fluconazole mouth rinse. The patient was examined using diagnostic exome sequencing at the age of 6 years, and a c.1162A>G (p.K388E) STAT1 gene mutation was identified. A diagnosis of CMC based on the STAT1 gene mutation was, thus, made. At the age of 8 years, the boy developed a malar-like rash on his face. We conducted tests for detection of antinuclear antibodies and anti-dsDNA antibodies, which showed positive results; therefore, systemic lupus erythematosus (SLE) was also suspected. Whole exome sequencing is important to diagnose rare diseases in children. A STAT1 gene mutation should be suspected in patients with chronic fungal infections with a thyroid disease and/or SLE.

Key words: Candidiasis, Chronic mucocutaneous, Lupus erythematosus, Systemic.

\section{Introduction}

Chronic mucocutaneous candidiasis (CMC) is a primary immune deficiency disorder characterized by increased susceptibility to chronic and recurrent infections of the skin, nails, and mucous membranes, usually without systemic involvement [1]. $\mathrm{CMC}$ manifests with differing clinical features as a result of heterogeneous gene mutations.

Gain-of-function (GOF) mutations in signal transducer and activator of transcription 1(STAT1; 600555) gene have been shown to cause autosomal dominant CMC (AD-CMC). However, other genetic mutations also contribute to the etiology of CMC. For example, autosomal recessive mutations in the autoimmune regulator gene induce autoimmune polyendocrinopathy candidiasis ectodermal dystrophy and STAT3 gene mutations cause hyper immunoglobulin E (IgE) syndrome; furthermore, autosomal recessive mutations in CARD9, heterozygous mutations in IL17F, and homozygous mutations in IL17RA or IL17RC genes

\footnotetext{
Received: 16 May 2018, Revised: 24 July 2018, Accepted: 25 July 2018, Published: 31 December 2018

${ }^{*}$ Corresponding author: Jeongho Lee, M.D., Ph.D. (D) http://orcid.org/0000-0003-4455-7540

Department of Pediatrics, Soonchunhyang University Seoul Hospital, 59 Daesagwan-ro, Yongsan-gu, Seoul 04401, Korea.

Tel: +82-2-709-9341, Fax: +82-2-709-9135, E-mail: ljh@schmc.ac.kr

Conflict of interest: The authors declare that they do not have any conflicts of interest.

(C) This is an open-access article distributed under the terms of the Creative Commons Attribution Non-Commercial License (http://creativecommons.org/licenses/by-nc/4.0/) which permits unrestricted non-commercial use, distribution, and reproduction in any medium, provided the original work is properly cited.

(c) Copyright 2018 by the Korean Society of Medical Genetics and Genomics 
cause $\mathrm{CMC}[2,3]$.

The diagnosis of CMC is based on clinical history, immunological features, and genetic analysis. In some studies, whole-exome sequencing (WES) was performed to identify GOF mutations in the STAT1 gene $[4,5]$. Impaired dephosphorylation mechanisms reportedly lead to gain of phosphorylating function $[6,7]$.STAT1 gene mutations manifest as clinical autoimmune disorders associated with thyroid disease, hepatitis and systemic lupus erythematosus (SLE). They also manifest as other conditions such as autoimmune diseases, aneurysms, infections, and cancer $[2,8]$.

The present case highlights the importance of WES in the diagnosis of CMC with thyroid disease and/or SLE. In addition, to the best of our knowledge, this is the first reported case of STAT1 gene mutation associated with CMC in Korea.

\section{Case}

A 20-month-old boy who did not grow in height during 3 months (height $80.8 \mathrm{~cm},<3 \mathrm{rd}$ percentile; weight $10.9 \mathrm{~kg}$, 5th10th percentile) was diagnosed with hypothyroidism and referred to us. Thyroid function tests were performed; they showed serum thyroid stimulating hormone (TSH) levels $>100 \mu \mathrm{lU} / \mathrm{mL}$ (normal range, 0.38-4.94 $\mu \mathrm{JU} / \mathrm{mL}$ ) and free T4 levels $<0.40 \mathrm{ng} /$ $\mathrm{dL}$ (normal range, $0.70-1.48 \mathrm{ng} / \mathrm{dL}$ ). Furthermore, mild gland enlargement and $11.6 \%$ elevation of uptake (normal range, 1.74.0\%) was shown in the thyroid scan. Based on these results, 33 $\mu \mathrm{g} /$ day $(3 \mu \mathrm{g} / \mathrm{kg} / \mathrm{day}$ ) of levothyroxine was prescribed and he had taken $60 \mu \mathrm{g} /$ day $(5.5 \mu \mathrm{g} / \mathrm{kg} /$ day) until he visited our hospital. He was admitted to other hospital and diagnosed hepatitis at 5 years and 2 months old (AST [aspartate aminotransferase], 1,966 IU/L [normal range, 0-40 IU/L]; ALT [alanine aminotransferase], 2,184 IU/L [normal range, 0-41 IU/L]). However, the cause was not known.

At the age of 5 years and 10 months, the boy visited our hospital with a recurrent oral thrush, vesicular rash, and hypothyroidism. His parents had no history of immunodeficiency or candidiasis. No apparent developmental delay or growth retardation was detected; his height was $114.7 \mathrm{~cm}$ (50th-75th percentile), and he weighed $24 \mathrm{~kg}$ (75th-90th percentile) for his age. His mother's height was $156 \mathrm{~cm}$ and father's height was $170 \mathrm{~cm}$ (mid-parental height: $169.5 \mathrm{~cm}$ ). The oral thrush and vesicular rash without pruritis on the abdomen, trunk, and extremities were recurrent and persistent (Figs. $1 \mathrm{~A}$ and $\mathrm{B}$ ). And he also had mild hepatosplenomegaly. The Institutional Review Board of Soonchunhyang Seoul Hospital in Seoul, Korea (IRB no. \#2017-06-005-002) approved the use of human clinical materials and blood in this study. Written informed consent for the research investigation was obtained from the parents before participation.

We performed allergy and immunological tests for the rash and thyroid function tests for hypothyroidism. No microorganism was detected in the throat swab culture for the oral thrush. Complete blood count (white blood cell count, 7,500 cells/ $\mu \mathrm{L}$ and absolute neutrophil count, 3,754 cells/ $\mu \mathrm{L}$ ) showed no abnormality; however, biochemistry markers evaluated during the outpatient follow-up indicated chronic hepatitis with mild elevation in the levels of the parameters of liver function test (AST, 39-133 IU/L [normal range, 0-40 IU/L]; ALT, 79-250 IU/L [normal range, $0-41 \mathrm{IU} / \mathrm{L}$ ], and total bilirubin, $0.2 \mathrm{mg} / \mathrm{dL}$ [normal range, $0-1.2 \mathrm{mg} / \mathrm{dL}$ ]). TSH (2.87 $\mu \mathrm{lU} / \mathrm{mL}$ [normal range, 0.25-4.0 $\mu \mathrm{lU} / \mathrm{mL}$ ]), free T4 (1.70 $\mathrm{ng} / \mathrm{dL}$ [normal range, $0.89-1.78 \mathrm{ng} / \mathrm{dL}$ ]), and T3 (177.30 ng/dL [normal range, $79-200 \mathrm{ng} / \mathrm{dL}$ ]) levels were within normal ranges. Because microsomal and thyroglobulinantibodies levels were elevated to more than $100 \mathrm{U} / \mathrm{mL}$ (normal range, $0-0.3 \mathrm{U} / \mathrm{mL}$ ) and $11.53 \mathrm{U} / \mathrm{mL}$ (normal range, $0-0.3 \mathrm{U} / \mathrm{mL}$ ),

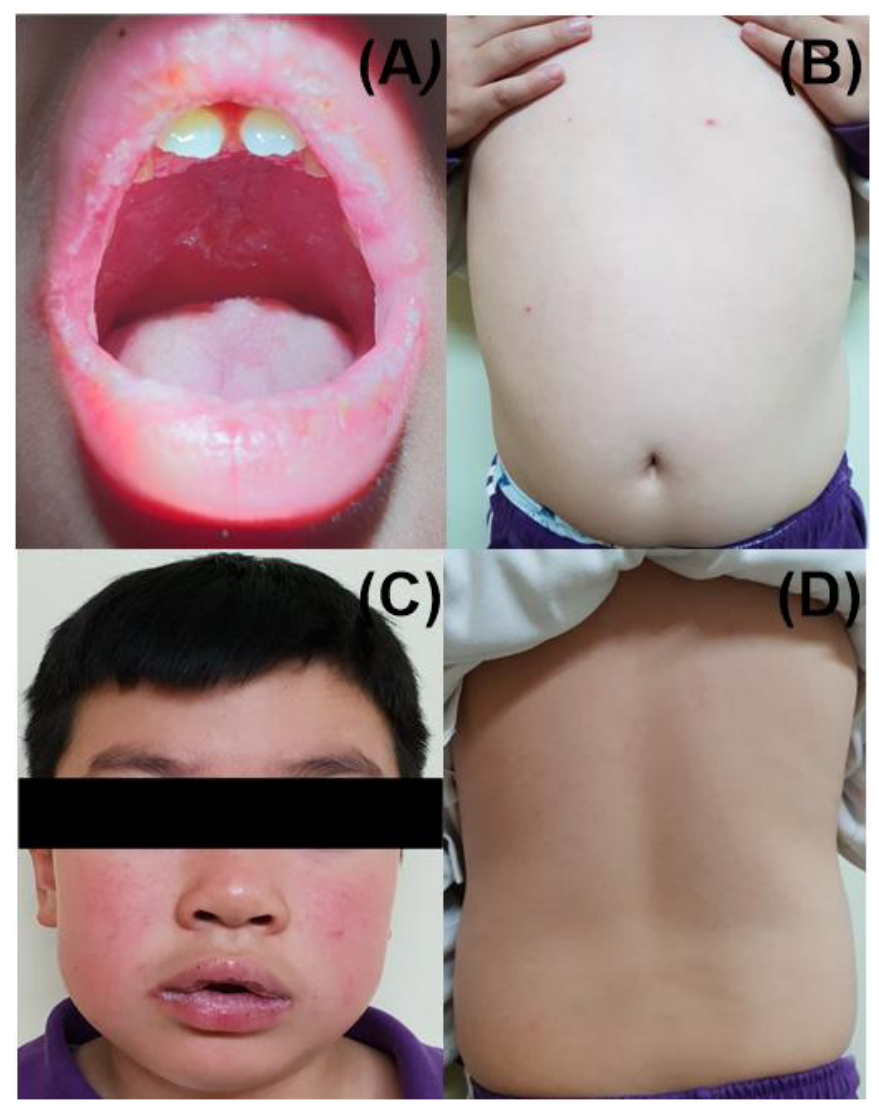

Fig. 1. Clinical features of chronic mucocutaneous candidiasis with systemic lupus erythematosus. Whitish oral thrush in the soft palate (A), vesicular rash on whole body without pruritis $(B)$, malar rash and panniculitis on face $(C)$, and erythematous rash on back (D). 
respectively, we made a diagnosis of autoimmune hypothyroidism. The result of thyroid stimulating immunoglobulin test was $0.02 \mathrm{IU} / \mathrm{L}$ (normal range, $0-1.0 \mathrm{IU} / \mathrm{L}$ ).

There was no evidence of any immunodeficiency disorder in the laboratory test results. The levels of $\lg G, \lg A, \lg M$, and $\lg E$

Table 1. Laboratory results of serum immunoglobulins, complement levels, and lymphocyte subgroups (rates and cell numbers)

\begin{tabular}{|c|c|c|}
\hline & Patient & Reference $^{a}$ \\
\hline $\lg G(\mathrm{mg} / \mathrm{dL})$ & 1,379 & $386-1,470$ \\
\hline $\lg A(m g / d L)$ & 77 & $29-256$ \\
\hline $\operatorname{lgM}(\mathrm{mg} / \mathrm{dL})$ & 158 & $37-224$ \\
\hline $\lg E(I U / m L)$ & 56.8 & $2-393$ \\
\hline IgG1 subclass (mg/dL) & 1,010 & $377.0-1,131.0$ \\
\hline IgG2 subclass (mg/dL) & 190 & $68.0-388.0$ \\
\hline IgG3 subclass (mg/dL) & 30.4 & $15.8-89.0$ \\
\hline IgG4 subclass (mg/dL) & 6.57 & $1.2-169.9$ \\
\hline C3 (mg/dL) & 172 & $90-180$ \\
\hline $\mathrm{C} 4$ (mg/dL) & 23 & $10-40$ \\
\hline CH50 (IU/mL) & 49 & $32-58$ \\
\hline CD3+T cells (\%) & 83.13 & $60-76$ \\
\hline CD3+T cells (cells/uL) & 2,715 & $1,200-2,600$ \\
\hline CD4+T cells (\%) & 44.40 & $31-47$ \\
\hline CD4+T cells (cells/ $\mu \mathrm{L})$ & 1,450 & $650-1,500$ \\
\hline CD8+T cells (\%) & 38.25 & $18-35$ \\
\hline CD8+T cells (cells/ $\mu \mathrm{L})$ & 1,249 & $370-1,100$ \\
\hline CD4+/CD8+ratio & 1.16 & $<1.0$ \\
\hline
\end{tabular}

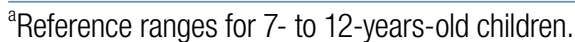

Ig, immunoglobulin; C, complement components; CD, cluster of differentiation. were within normal limits, and the levels of subclasses $\lg \mathrm{G} 1$, $\lg \mathrm{G} 2, \lg \mathrm{G} 3$, and $\lg \mathrm{G} 4$ were also normal. The percentages and absolute lymphocyte count (cluster of differentiation [CD]3, CD4, and CD8) were not decreased (Table 1).

We prescribed levothyroxine $62.5 \mu \mathrm{g} /$ day $(2.6 \mu \mathrm{g} / \mathrm{kg} /$ day $)$ and fluconazole mouth rinse due to hepatic toxicity. However, his oral thrush was persistent and the vesicular rash kept recurring. When the patient was 6 years old, we advised genetic counseling to his parents, and he underwent WES. A heterozygous c.1162A $>$ G (p.K388E) mutation was detected in STAT1 (Fig. 2). Based on that, we confirmed his condition as CMC with hypothyroidism and hepatitis.

At the age of 8 years, the boy developed malar rash and panniculitis on the face and erythematous rash on the back (Fig. $1 \mathrm{C}$ and D). We suspected SLE due to the STAT1 gene mutation. Laboratory test results were positive for antinuclear antibodies ( $1: 40)$ and anti-ds-DNA (7.20 IU/mL [normal range, 0-7.0 IU/ $\mathrm{mL}]$ ) antibodies. Rheumatoid factor levels were within normal limits (11 IU/mL [normal range, $0-14 \mathrm{IU} / \mathrm{mL}$ ]). Thus, the patient was diagnosed with SLE as well and was followed up in the outpatient clinic.

\section{Discussion}

We diagnosed a patient as having clinical manifestations of a STAT1 gene mutation detected using WES. STAT1 mutations lead to AD-CMC, characterized by defective Th1 and Th17 responses that inhibit the production of interleukin (IL)-17, IL-22,

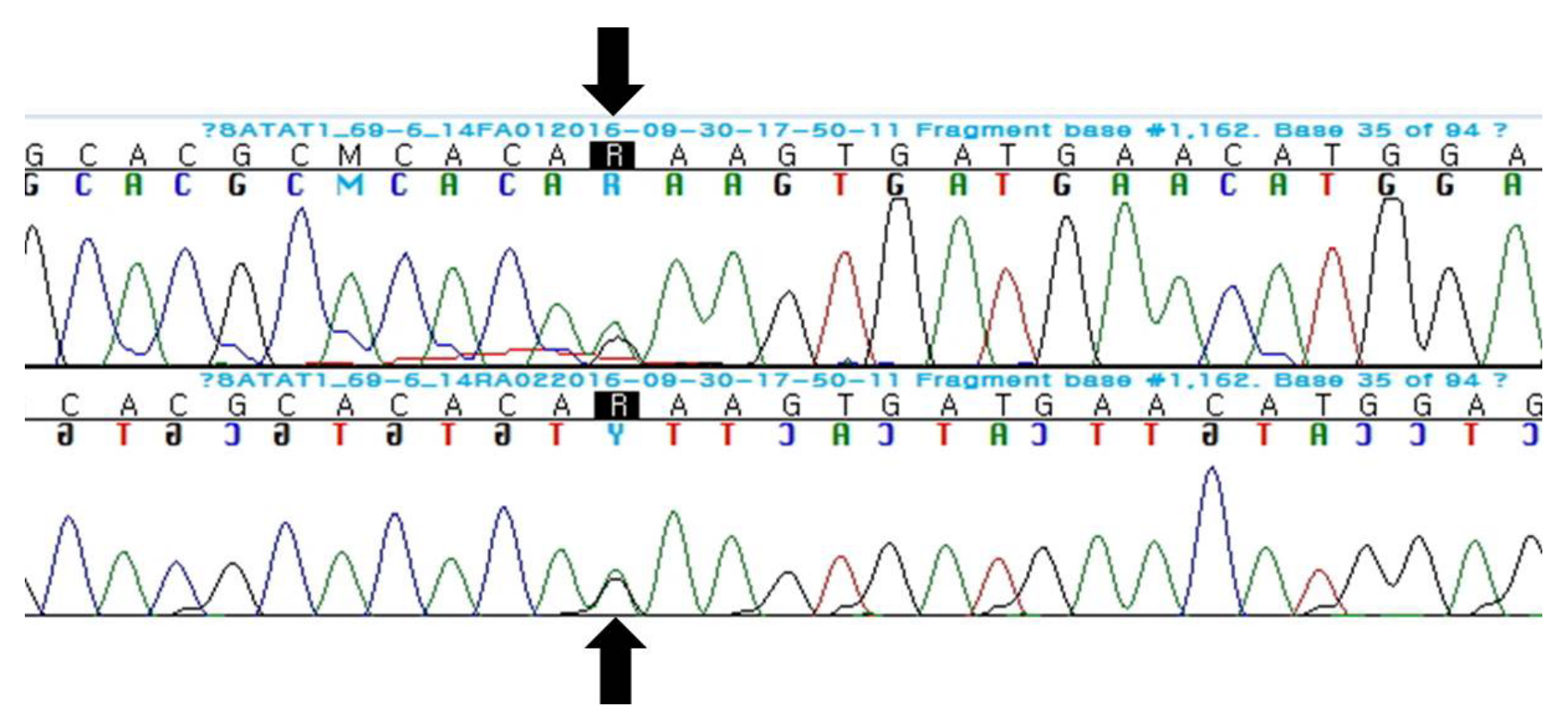

Fig. 2. Identification of a point mutation of the STAT1 gene. The patient is carrying compound heterozygous c.1162A $>$ G (p.K388E) mutation. 
interferon (IFN)- $\alpha / \beta$, and IFN- $\gamma$; these are important antifungal defense factors of the skin and mucosa $[1,4,8,9]$. Neither immunodeficiency on serological examination nor a positive culture of Candida species was detected in our patient. However, the chronic and recurrent oral thrush and vesicular rash as well as the concomitant autoimmune hypothyroidism and chronic hepatitis helped us suspect the diagnosis that was confirmed using WES. In addition, we later found that the patient had developed signs of SLE that can also be due to the STAT1 gene mutation.

In a study by Depner et al. [3], oral candidiasis (73\%), esophageal candidiasis (65\%), and aphthous stomatitis (69\%) were the most common clinical manifestations; although SLE was not present in any patient, autoimmune thyroid disease was present in 44\% of patients and was the most common autoimmune comorbidity. In addition, studies have shown an association between SLE and STAT1 mutations. Liu et al. [8] showed in their study that thyroid autoimmunity in eight patients and SLE in one patient were confirmed by detection of STAT1 mutations. Furthermore, Toubiana et al. [2] reported concomitant SLE and autoimmune chronic hepatitis in $2 \%$ cases of $C M C$, respectively. Liang et al. [7] showed that STAT1 mutations are necessarily associated with SLE development. In Japan, Takezaki et al. [10] reported two cases of $\mathrm{CMC}$ with bronchiectasis and autoimmune hypothyroidism diagnosed using detection of STAT1 mutations. We can find similar to this paper in one more report associated with STAT1 mutations that a case of CMC with hypothyroidism and chronic autoimmune hepatitis was presented [11].

Depner et al. [3], 35 of 57 (61\%) CMC patients had a heterozygous mutation in STAT1. Two research groups investigating CMC revealed the impact of STAT1 mutations detected using WES and Sanger sequencing for genetic diagnosis and presented a variety of clinical manifestations through long-term followups $[4,5]$. We also used WES for diagnostic confirmation in our patient.

Studies have reported gain of function in several dozen STAT1 mutations. In the present case, we detected a c.1162A $>G$ ( $p$. $\mathrm{K} 388 \mathrm{E}$ ) mutation that was first reported in a study by Frans et al. [12]. Furthermore, it was reported by Wang et al. [13]; however, their cases differ from the present case because only nail involvement and oral thrush were observed in them without the other complications observed in the present case.

No standard treatment for CMC exists, and the choice of treatment is difficult due to the various clinical features. However, treatment options for AD-CMC have been described; most common treatment includes using prophylactic antifungal agents.
Because of the proven underlying immunologic and genetic defects in patients with $\mathrm{AD}-\mathrm{CMC}$, granulocyte colony-stimulating factor (G-CSF) has been used to improve the chemotactic functions of neutrophils. Moreover, ruxolitinib, a Janus kinase (JAK) 1/2 inhibitor, and a histone deacetylase inhibitor are being tested in trials [14]. Wildbaum et al. [15], continuous G-CSF (filgrastim) therapy presented that a complete clinical remission of female patient who was 59-years-old patient suffered from CMC for more than 33 years. G-CSF treatment for last 16 years had an effect on activation of STAT3 increasing Th17 cell development or stimulating IL-17 secretion and of SOCS1 expression which makes inhibition of STAT1 and reduced IFN- $\gamma$ secretion. Ruxolitinib effects on JAK1/2 pathway signaling and activation of transcription (JAK-STAT) pathways. JAK $1 / 2$ inhibitor that is already known as US Food and Drug Administration approved for the treatment of myelofibrosis. A case of treatment of oral ruxolitinib showed that 28-years-old woman experienced hair regrowth and unexpectedly resolved the oral candidiasis [16].

In the Republic of Korea, dermatologists have reported many CMC cases, but without genetic evaluations for STAT1 mutations. To the best of our knowledge, this is the first report on a STAT1 mutation in a CMC case in Korea [17-20]. It highlights the need for more communication among different specialists to discuss and evaluate the genetic diagnosis and treatment. Moreover, familial genetic mutations should be evaluated to help with the interpretation of clinical findings. It would have been better for the patient if his parents had agreed for genetic testing earlier.

In conclusion, WES plays a key role in the diagnosis of rare diseases like CMC. In addition, owing to many mutations and various genetic patterns in $\mathrm{CMC}$, WES is very important. Furthermore, we need to introduce CMC panel which is already used in abroad. In cases with negative culture results, like the present one, the accompanying disorders like chronic/recurrent oral thrush, hypothyroidism, hepatitis, and SLE should prompt the question whether a genetic abnormality like a STAT1 mutation is present. In addition, long-term follow-ups in children are crucial for diagnosing rare diseases.

\section{Acknowledgements}

This work was supported by the Soonchunhyang University Research Fund. 


\section{References}

1. van de Veerdonk FL, Plantinga TS, Hoischen A, Smeekens SP, Joosten LA, Gilissen $C$, et al. STAT1 mutations in autosomal dominant chronic mucocutaneous candidiasis. N Engl J Med 2011;365:54-61.

2. Toubiana J, Okada S, Hiller J, Oleastro $M$, Lagos Gomez $M$, Aldave Becerra JC, et al. Heterozygous STAT1 gain-of-function mutations underlie an unexpectedly broad clinical phenotype. Blood 2016;127: 3154-64.

3. Depner M, Fuchs S, Raabe J, Frede N, Glocker C, Doffinger R, et al. The extended clinical phenotype of 26 patients with chronic mucocutaneous candidiasis due to gain-of-function mutations in STAT1. J Clin Immunol 2016;36:73-84.

4. Dhalla F, Fox H, Davenport EE, Sadler R, Anzilotti $C_{1}$ van Schouwenburg PA, et al. Chronic mucocutaneous candidiasis: characterization of a family with STAT-1 gain-of-function and development of an exvivo assay for Th17 deficiency of diagnostic utility. Clin Exp Immunol 2016;184:216-27.

5. Soltész B, Tóth B, Shabashova N, Bondarenko A, Okada S, Cypowyj $S$, et al. New and recurrent gain-of-function STAT1 mutations in patients with chronic mucocutaneous candidiasis from Eastern and Central Europe. J Med Genet 2013;50:567-78.

6. Smeekens SP, Plantinga TS, van de Veerdonk FL, Heinhuis B, Hoischen A, Joosten LA, et al. STAT1 hyperphosphorylation and defective IL12R/ IL23R signaling underlie defective immunity in autosomal dominant chronic mucocutaneous candidiasis. PLoS One 2011;6:e29248.

7. Liang $Y, X u$ WD, Yang $X K$, Fang $X Y$, Liu $Y Y, N i$ J, et al. Association of signaling transducers and activators of transcription 1 and systemic lupus erythematosus. Autoimmunity 2014;47:141-5.

8. Liu L, Okada S, Kong XF, Kreins AY, Cypowyj S, Abhyankar A, et al. Gain-of-function human STAT1 mutations impair IL-17 immunity and underlie chronic mucocutaneous candidiasis. J Exp Med 2011; 208:1635-48.

9. Conti HR, Shen $F$, Nayyar $N$, Stocum E, Sun JN, Lindemann MJ, et al. Th17 cells and IL-17 receptor signaling are essential for mucosal host defense against oral candidiasis. J Exp Med 2009;206:299-311.
10. Takezaki S, Yamada M, Kato M, Park MJ, Maruyama K, Yamazaki Y, et al. Chronic mucocutaneous candidiasis caused by a gain-of-function mutation in the STAT1 DNA-binding domain. J Immunol 2012;189: 1521-6.

11. Hori $T$, Ohnishi $H$, Teramoto $T$, Tsubouchi $K$, Naiki $T$, Hirose $Y$, et al. Autosomal-dominant chronic mucocutaneous candidiasis with STAT1-mutation can be complicated with chronic active hepatitis and hypothyroidism. J Clin Immunol 2012;32:1213-20.

12. Frans $G$, Moens $L$, Schaballie $H$, Van Eyck L, Borgers $H$, Wuyts $M$, et al. Gain-of-function mutations in signal transducer and activator of transcription 1 (STAT1): chronic mucocutaneous candidiasis accompanied by enamel defects and delayed dental shedding. J Allergy Clin Immunol 2014;134:1209-13.e6.

13. Wang $X$, Zhang $R$, Wu W, Wang $A$, Wan $Z$, van de Veerdonk $F L$, et al. New and recurrent STAT1 mutations in seven Chinese patients with chronic mucocutaneous candidiasis. Int J Dermatol 2017;56:e30-3.

14. van de Veerdonk FL, Netea MG. Treatment options for chronic mucocutaneous candidiasis. J Infect 2016;72 Suppl:S56-60.

15. Wildbaum G, Shahar E, Katz R, Karin N, Etzioni A, Pollack S. Continuous G-CSF therapy for isolated chronic mucocutaneous candidiasis: complete clinical remission with restoration of IL-17 secretion. J Allergy Clin Immunol 2013;132:761-4.

16. Higgins $E_{1}$ Al Shehri T, McAleer MA, Conlon N, Feighery C, Lilic D, et al. Use of ruxolitinib to successfully treat chronic mucocutaneous candidiasis caused by gain-of-function signal transducer and activator of transcription 1 (STAT1) mutation. J Allergy Clin Immunol 2015;135: 551-3.

17. Chun TJ, Ro BI. Chronic mucocutaneous candidiasis in Korea. Korean J Med Mycol 1999;4:104-8.

18. Choi KH, Kim HS, Kim HO, Park YM. Familial chronic mucocutaneous candidiasis. Korean J Med Mycol 2009;14:28-32.

19. Park JH, Yoo CS, Kil MS, Kim CW, Kim SS, Kim KH. A case of chronic mucocutaneous candidiasis occurring in a patient with scrofuloderma-like BCGitis. Korean J Med Mycol 2010;15:175-81.

20. Lee HK, Seo SJ, Ro BI. A case of chronic mucocutaneous candidiasis. Ann Dermatol 1995;7:62-5. 